\title{
From the Desk of Editor-in-Chief
}

\author{
S. R. Bhatt ${ }^{1}$
}

(c) ICPR 2018

The XXXV Volume of JICPR (January 2018) is out for your reading, perusal, critical comments and suggestions. It contains papers drawn both from Western and Indian philosophical traditions. They deal with basic epistemological, ontological, ethical and linguistic issues which are significant in philosophical discourse.

Philosophy is a view of reality and a way of life based on it. It has both theoretical and practical dimensions. What is more important is that philosophical reflections should be life oriented, socially useful and of contemporary relevance. For this we have to bank upon past heritage and be benefitted by the wisdom of past seers, sages and thinkers. But mere repetition of the past without drawing out its present day utility may not be meaningful.

Philosophy is a foundational discipline, and therefore this basic character of philosophy has to be kept in mind so as to provide needed guidance to other disciplines of knowledge in terms of methodology, conceptual analysis, theory construction and linguistic analysis.

So far we have not paid adequate attention to Afro-Asian philosophies. Wellresearched papers are invited in this area. There are seminal ideas, concepts and theories contained therein from which we may profit. Their threadbare analysis may enrich our philosophizing.

The task of philosophy is to raise issues based on our lived experiences and providing cogent, convincing and conducive solutions to them. This involves practical concerns and approaches based on collective thinking. For this purpose, a separate section inviting judicious comments is being introduced. We also plan to have another section of inviting questions and queries for further reflection. Philosophizing is not a 'closed enterprise' and there has to be open-endedness along with innovative ideas. Then only it becomes lively and useful. It must open up new

S. R. Bhatt

jicpr.editor@gmail.com

1 Indian Council of Philosophical Research, New Delhi, India 
vistas in the modes of thinking and ways of living. I wish and hope that philosophers and scholars of philosophy will stand up to this task and discharge their academic and social obligations. 